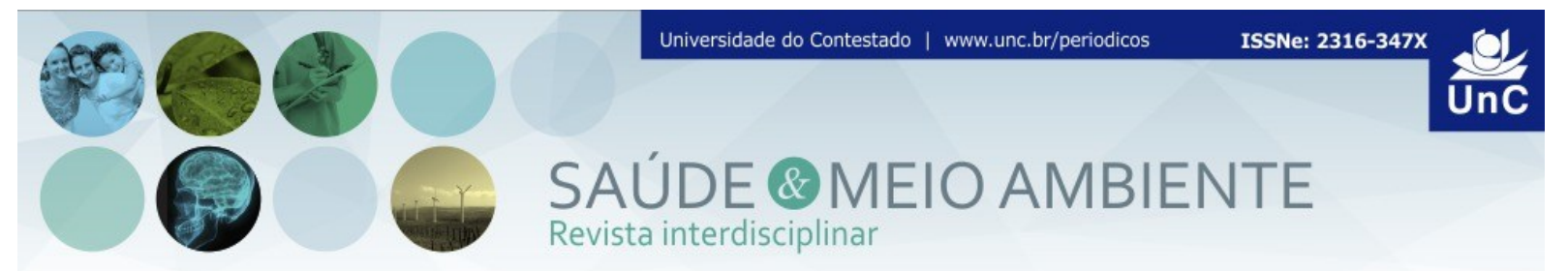

\title{
REALIDADE E DESAFIOS DAS ESFS PARA A EXECUÇÃO DA PRIMEIRA DOSE IMEDIATA DE ANTIBIÓTICO PARA CRIANÇAS EM SITUAÇÃO DE DOENÇA
}

\author{
Adriana Adriana Moro Wieczorkievicz ${ }^{1}$ \\ Patricia Soares ${ }^{2}$ \\ Camila Heiden Glonek Junkes ${ }^{3}$
}

\begin{abstract}
RESUMO: No Brasil ainda é grande o índice de mortalidade infantil por doenças infectocontagiosas, desta forma, várias são as ações para a melhoria na saúde que têm sido criadas e implementadas pelo Ministério da Saúde do Brasil. Uma dessas ações é a campanha primeira dose imediata de antibióticos, lançada no ano de 2011 pela pastoral da criança em parceria com o governo Federal. Esta visa à prevenção dos agravos à saúde infantil e diminuir os índices de mortalidade. Desta forma, o objetivo geral desta pesquisa foi identificar as realidades e os desafios das Estratégias em Saúde da Família (ESF) de um município do Planalto Norte Catarinense para a execução da primeira dose imediata e supervisionada de antibiótico. A coleta de dados aconteceu no período de julho a agosto de 2012 nas sete estratégias de Saúde da Família do Município do planalto norte catarinense. Os dados foram coletados por meio de entrevista direta com os enfermeiros das ESFs do município e um check-list para avaliação da estrutura física das unidades para verificar a adequação das mesmas em uma eventual reação ao antibiótico. Os dados alcançados foram analisados a luz do referencial teórico e das recomendações do Ministério da Saúde. Os resultados encontrados apontam que ainda há falta de conhecimento e divulgação da campanha para realização da primeira dose do antibiótico já depois de sua prescrição na unidade básica de saúde.
\end{abstract}

Palavras-chave: Mortalidade infantil. Antibiótico. Saúde da criança.

\section{REALITY AND CHALLENGES OF ESFS FOR EXECUTION OF FIRST DOSE IMMEDIATE OF ANTIBIOTICS FOR CHILDREN IN DISEASE SITUATION}

ABSTRACT: In Brazil there is a huge infant mortality rate for infectious diseases, thus several actions aimed at improving the health of these have been created and implemented by the Ministry of Health of Brazil. One such action is the immediate campaign first dose of antibiotics, launched in 2011 by the ministry of children in partnership with the Federal government. This aims at the prevention of health hazards and reduces infant mortality rates. The objective of this research is to identify the realities and challenges of the Family Health Strategy in a city in northern

\footnotetext{
${ }^{1}$ Doutoranda em Políticas Públicas UFPR. Professora da Universidade do Contestado. Membro do Grupo de Pesquisa NUPESC - UnC. Santa Catarina. Brasil. E-mail: adri.moro@gmail.com

${ }^{2}$ Enfermeira. Universidade do Contestado. Santa Catarina. Brasil. E-mail: p nytha@hotmail.com

${ }^{3}$ Residente em saúde da criança pelo hospital de Clínicas de Porto Alegre/RS. Graduada em Enfermagem pela Universidade do Contestado - UnC campus Mafra/SC. Rio Grande do Sul. Brasil. E-mail: milajunkes@yahoo.com.br
}

Saúde Meio Ambient. v. 5, n. 1, p. 78-88, jan./jun. 2016

ISSN 2316-347X 
Santa Catarina Plateau for immediate implementation of the first dose of antibiotic and supervised. Data collection took place from July to August 2012 in the seven strategies of Family Health in the city in northern Santa Catarina. Data were collected through direct interviews with nurses from the county ESFs and a checklist for evaluating the physical structure of the units to check the adequacy of the same in a possible reaction to the antibiotic. The data obtained were analyzed in light of the theoretical framework and the recommendations of the Ministry of Health. The results show that there is still a lack of knowledge and dissemination of the campaign to implement the first dose of antibiotic already after his prescription in primary care unit.

Keywords: Infant mortality. First dose. Child health.

\section{INTRODUÇÃO}

O papel da criança e sua importância diante da sociedade têm mudado ao longo da história dentro da sociedade e das culturas. A pediatria dentro de uma prática assume o papel de tornar esse processo de cuidado infantil uma ciência verdadeira, com ações amplas e adaptadas à tecnologia social e cultural, procurando de forma crescente focar nos cuidados a promoção da saúde e prevenção de agravos, que abrangem desde o pré-natal até a fase da adolescência (ALCÂNTARA, 1983).

A história antiga mostra que cuidados a criança não existiam ou eram escassos e na maioria dos casos os povos a ignoravam. Eram cometidas atrocidades, como o sacrifício de crianças para equilíbrio dos sexos, por medidas econômicas, na ocasião de grandes flagelos para não serem empecilhos às grandes caminhadas, por medidas religiosas, imolações de crianças em honra de deuses e as cruéis práticas de espargir o sangue de crianças pelos campos para beneficiar as colheitas e por motivos supersticiosos. No decorrer dos séculos grandes vozes buscavam redimir a alma da criança através do batismo e artistas da história moderna provaram ao mundo através de grandes obras que a criança tinha personalidade e não era um adulto em miniatura (AGUIAR, 1996).

No Brasil foi criado em 1984 um programa de assistência integral a criança que visava enfrentar fatores de morbidade e melhorar o atendimento à criança que buscava aumentar a cobertura de serviços, acompanhamento, crescimento e desenvolvimento, assistência no aleitamento materno, infecções respiratórias, diarreicas e doenças previsíveis pela imunização (VERISSIMO et al., 2003).

A legislação brasileira, por meio do Estatuto da Criança e do Adolescente (ECA), reforça o compromisso pela promoção do bem estar desses pequenos cidadãos. Responsabilidade esta que não é apenas da família, mas do estado e da sociedade como um todo. O cuidado com a saúde infantil está entre as ações essenciais do Ministério da Saúde. Os programas desenvolvidos buscam oferecer um atendimento médico mais humano, de qualidade para as crianças. Mas apesar 
dos avanços, os indicadores de saúde demonstram que ainda falta um longo caminho a percorrer para garantir as crianças brasileiras o direito integral a saúde, como assumido em nossas leis (COSTA, 1998).

Neste contexto, a Pastoral da Criança é reconhecida como uma das mais importantes organizações do mundo a trabalhar em ações de combate à mortalidade infantil e melhoria da qualidade de vida das crianças e suas famílias. Organismo de ação social da Conferência Nacional dos Bispos do Brasil (CNBB), a Pastoral da Criança é uma instituição de base comunitária que tem seu trabalho baseado na solidariedade e na partilha do saber. Tem como objetivo promover o desenvolvimento integral das crianças pobres, em seu contexto familiar e comunitário, a partir de ações preventivas de saúde, nutrição, educação e cidadania, realizadas por mais de 228 mil voluntários capacitados. Trabalha em prol das crianças, famílias e comunidades, sem distinção de raça, cor, profissão, nacionalidade, sexo, credo religioso ou político (BOUFLEUR, 2011).

Quando se discute as ações em prol da saúde das crianças, não se pode esquecer que um dos principais componentes da mortalidade infantil, são as doenças causadas por bactérias. Todas as doenças bacterianas na infância devem ser diagnosticadas e tratadas imediatamente, pois o patógeno causador da afecção pode repercutir imediatamente em consequências negativas para a piora do estado de saúde da criança. O processo patológico das doenças bacterianas na criança acontece rapidamente, a bactéria invade o organismo, se multiplica rapidamente e inicia os sintomas logo após. Como o organismo da criança dispõe de menos agentes defensores inicia-se um processo muito rápido e grande de crescimento bacteriano que pode provocar muitas lesões na criança podendo levar a morte em até 48 horas dependendo do tipo de bactéria adquirida (NÓRCIO, 2011).

Neste sentido, o marco que indiscutivelmente mudou a história da medicina foi a descoberta e a introdução de antimicrobianos no atendimento de saúde. Além de ser a principal arma no combate às doenças infecciosas em pediatria, também ocupam a liderança nas intervenções terapêuticas nessa faixa etária (FERREIRA, 2005). Sabe-se que o tratamento com antibióticos é muito eficaz, desde que seja administrado na dose e no tempo correto. Os efeitos adversos que podem ocorrer após administração podem ser graves e necessitar de auxilio de outras drogas e aparatos médicos imediatamente, por isso, todas as unidades aonde são administradas as drogas devem possuir um protocolo de atendimento à emergências. Após a administração dos antibióticos o paciente deve ser observado, pois pode apresentar uma série de reações em questão de minutos, reações estas que podem variar para cada indivíduo (FERREIRA, 2005).

O uso incorreto ou preparo incorreto da medicação pode acarretar em uma série de problemas ou simplesmente não surtir o efeito desejado. Os problemas decorrentes podem variar dependendo da forma do preparo e os efeitos podem ser simples reações adversas ou até a morte quando se tratam de uma necessidade o uso e efeito imediato dessa medicação (BRASIL, 2007).

A saúde da criança é uma grande preocupação para pais e sociedade em geral. Segundo a Organização Mundial da Saúde (2011) até os cinco anos de idade, 
as doenças infecciosas podem causar grandes danos à criança e podem levar a morte. Assim, para que se evitem fatalidades, o processo de doença foi estudado e hoje existem medicamentos que podem melhorar o estado dessas enfermidades quando administrado em tempo correto.

No Brasil há um grande índice de internamento hospitalar e mortalidade infantil por doenças bacterianas, principalmente as respiratórias. Diante desses dados, a Pastoral da Criança com apoio do Ministério da Saúde, lançou em 2011, a campanha para administração imediata da primeira dose de antibiótico nas unidades básicas de saúde. Segundo dados da Pastoral da Criança, com a efetivação da campanha poderão evitar até quatro mil mortes de crianças/ano por infecção bacteriana (OMS, 2011).

A estratégia de administração da primeira dose de antibiótico na unidade onde o mesmo foi receitado está sendo divulgada em rede nacional, mas ainda percebe-se a falta de conhecimento da sociedade e dos profissionais de saúde sobre a importância da primeira dose (dose de ataque) do antibiótico supervisionada ainda na unidade básica de saúde (BOUFLEOR, 2011). Vale salientar que a Pastoral da Criança foi quem lançou o projeto da campanha primeira dose imediata e buscou parceria com o governo federal que promoveu o desenvolvimento do programa com o objetivo de diminuir a mortalidade infantil por doenças bacterianas.

Com a implantação desta prática, de administrar a primeira dose dos antibióticos nas unidades básicas de saúde, a equipe de enfermagem tem a oportunidade de avaliar quais as dificuldades da família na administração, preparação e continuação do tratamento no domicilio. Caso perceba-se que o cuidador da criança tem dificuldade para administrar o tratamento, o enfermeiro poderá mobilizar outras estratégias, como contatar os agentes comunitários de saúde que poderão auxiliar realizando visita domiciliar ou, em concordância com o clinico encaminhar a criança para internação.

Todavia, para se efetivar esta medida as unidades básicas de saúde precisam ter uma conformação mínima, tanto no que diz respeito à estrutura física, como recursos materiais e humanos. Portanto, o objetivo deste estudo foi identificar as realidades e os desafios das Estratégias de Saúde da Família de um município do Planalto Norte Catarinense para administração da primeira dose imediata e supervisionada de antibiótico, conforme sugerido pela pastoral da criança em parceria com o Ministério da Saúde.

\section{MATERIAL E MÉTODOS}

Trata-se de uma pesquisa de campo de natureza básica, descritiva e exploratória com abordagem qualitativa. A pesquisa foi aprovada pelo comitê de ética da Universidade do Contestado sob o número 52806/2012. 
A pesquisa foi realizada em um município do planalto norte catarinense, no qual há sete Estratégias da Saúde da Família (ESF) onde cada uma dispõe de uma estrutura física localizada em diferentes áreas de abrangência. Para compor o universo foram selecionados para a amostra sete enfermeiros destas unidades e que se disponibilizaram a assinar o termo de consentimento livre e esclarecido.

A coleta de dados foi realizada em quatro etapas. A primeira etapa tratou de elucidar a amostra através de abordagem verbal sobre a intenção e como ocorreria o estudo com exposição do título, objetivos e procedimento para coleta de dados e obter o termo de aceite do responsável pela secretaria de saúde do município; $\mathrm{Na}$ segunda etapa foi definida a amostra, contato com os participantes e agenda do horário para a avaliação da unidade; Na terceira etapa os enfermeiros das ESF responderam ao questionário semiestruturado que continha 15 perguntas estruturadas em dois eixos temáticos, sendo o primeiro sobre a estrutura que já tinham no serviço para a realização da dose do antibiótico logo após a consulta e o segundo conjunto de perguntas versava sobre os desafios que os enfermeiros observavam no campo para a realização da atividade questionada. Tratou-se de um questionário com perguntas abertas e fechadas e foi realizado o preenchimento de um check-list no qual continha os equipamentos e insumos necessários a realziação do antibiótico na unidade, propondo dessa forma uma avaliação da unidade, seus materiais e espaço físico; Na quarta etapa os dados coletados foram tabulados e discutidos a luz do referencial teõrico e das recomendações da Sociedade Brasileira de Pediatria e do Minist+erio da Saúde. município.

Amostra foi composta por $100 \%(n=7)$ dos enfermeiros que atuam nas ESF do

\section{RESULTADOS E DISCUSSÃO}

O presente artigo é parte de um estudo maior sobre a realidade e os desafios enfrentados para realização da campanha primeira dose imediata de antibióticos nas unidades onde houve o primeiro atendimento a criança adoecida, tendo sido o estudo realizado nas ESF e com os enfermeiros responsáveis pelas unidades no município universo da pesquisa.

No quadro 01 visualiza-se o perfil da amostra pesquisada. Observa-se que a idade dos enfermeiros variou de 24 a 41 anos, enquanto a média de tempo de formação variou de um a oito anos, prevalecendo os cinco primeiros anos de formado, com tempo de serviço na mesma unidade de no máximo cinco anos e mínimo de um ano. 
Realidade e desafios das ESFs para a execução da primeira dose imediata de antibiótico para crianças em situação de doença

Quadro 1 - Perfil da amostra pesquisada

\begin{tabular}{|c|c|c|c|}
\hline Codinome & Idade & Tempo de formação & Tempo que trabalha na unidade \\
\hline ESF 01 & 32 anos & 06 anos & 03 anos \\
\hline ESF 02 & 24 anos & 03 anos & 01 ano \\
\hline ESF 03 & 26 anos & 04 anos & 02 anos \\
\hline ESF 04 & 24 anos & 02 anos & 02 anos \\
\hline ESF 05 & 41 anos & 04 anos & 03 anos \\
\hline ESF 06 & 28 anos & 06 anos & 05 anos \\
\hline ESF 07 & 32 anos & 08 anos & \\
\hline
\end{tabular}

No quadro 02 fica evidente que $57 \% \quad(n=4)$ dos enfermeiros não têm conhecimento sobre a campanha "primeira dose imediata".

Quadro 2 - Conhecimento dos enfermeiros em relação à campanha primeira dose imediata do antibiótico.

\begin{tabular}{|c|c|}
\hline ESF 01 & NÃO \\
\hline ESF 02 & SIM \\
\hline ESF 03 & SIM \\
\hline ESF 04 & NÃO \\
\hline ESF 05 & NÃO \\
\hline ESF 06 & NÃO \\
\hline ESF 07 & SIM \\
\hline
\end{tabular}

A campanha "primeira dose imediata" é resultado de vários estudos da Pastoral da Criança com o apoio do Ministério da Saúde, secretarias de saúde, Sociedade Brasileira de Pediatria, Academia Brasileira de Pediatria e a Unicef que estão divulgando a campanha usando recursos da mídia, realizando seminários e informando as secretarias que são encarregadas de organizar a distribuição dos antibióticos e a realização da campanha (NEUMANN, 2011).

Conforme descrito no protocolo de saúde integral da criança de zero a cinco anos de idade, o acompanhamento da criança é um fator importante e fundamental, pois permite avaliar precocemente transtornos que afetam a saúde em geral da criança. Assim o clínico e equipe passam informações para a mãe, ou cuidador, sobre o estado de normalidade ou de risco em casos de doenças. Desta forma a mãe conhece os sinais de perigo e busca o atendimento médico em tempo hábil, evitando complicações e até o óbito infantil (FAJARDO, et al., 2004). 
O gráfico 01 mostra a principal dificuldade para a realização da campanha primeira dose imediata de antibiótico, segundo o relato dos enfermeiros das ESF pesquisadas.

Gráfico 1 - Dificuldades relatadas pelos enfermeiros para realização da campanha

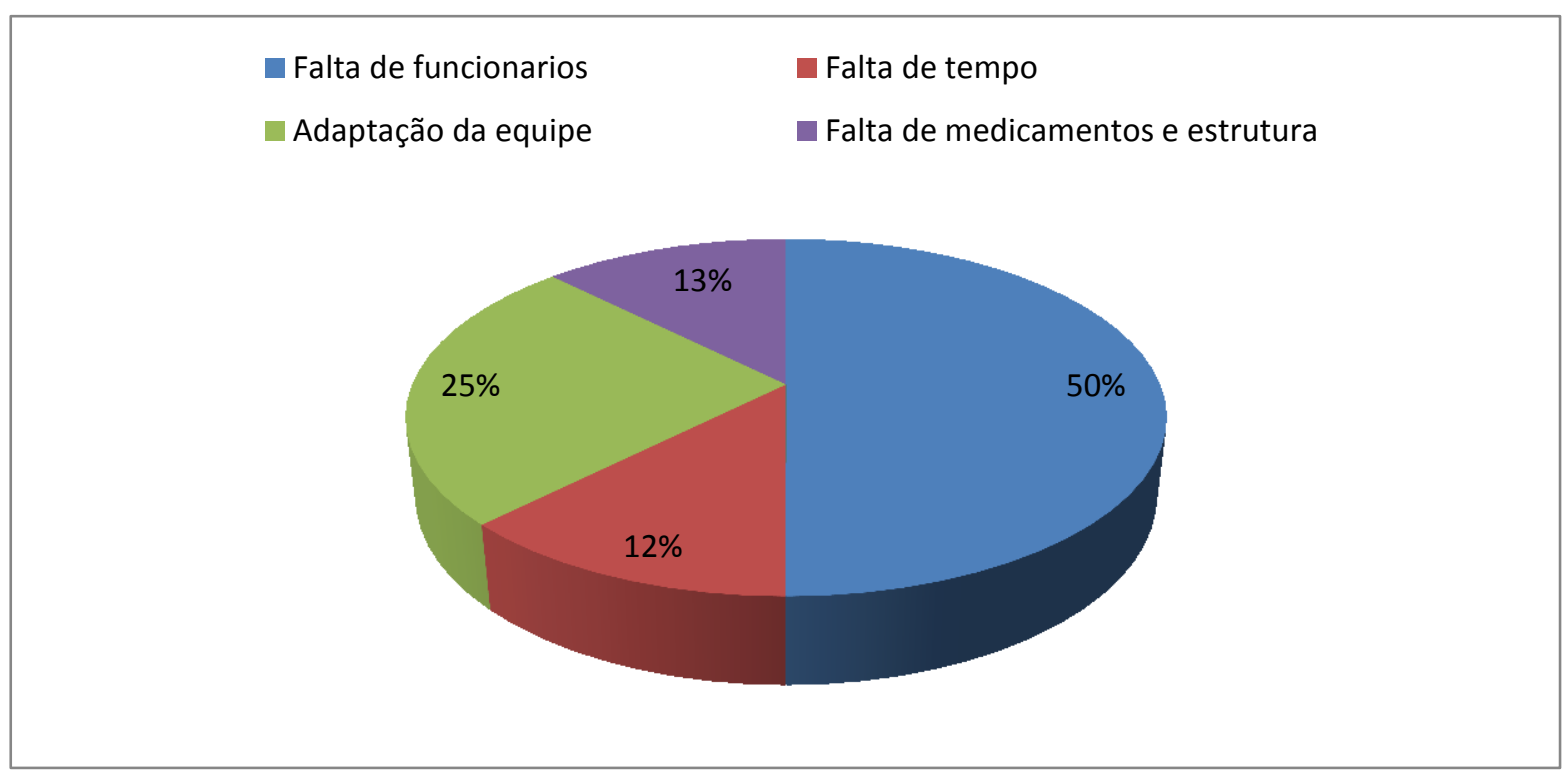

Os principais problemas relatados pelos enfermeiros foram, falta de funcionários, pois as unidades trabalham com o número exato de funcionários para cada função; excesso de atividades para serem realizadas, causando sobrecarga da equipe e; falta de tempo, pois o trabalho de enfermagem implica não somente na realização de uma técnica, mas na assistência humanizada, que fica prejudicada quando há sobrecarga de trabalho.

Outro problema citado é a adaptação da equipe, que muitas vezes tem o tempo e os materiais necessários para realização de uma nova atividade, mas está programada para realizar as mesmas atividades de sempre, não acompanhando as mudanças da sociedade e necessidades de melhora no atendimento. A enfermeira gerencial também é responsável pela motivação da equipe e divisão de afazeres assim podendo implantar novos desafios para a equipe.

No quadro 05 pode-se visualizar quem são os responsáveis, em cada unidade de saúde, pela dispensação e orientação sobre o uso das medicações.

Quadro 5 - Responsável pela dispensação e orientação da forma que deve ser preparado e administrado o medicamento.

\begin{tabular}{|c|c|}
\hline UNIDADE & RESPONSÁVEL PELA DISPENSAÇÃO \\
\hline ESF 01 & Qualquer funcionário presente na farmácia \\
\hline ESF 02 & Técnica em enfermagem \\
\hline ESF 03 & Auxiliar de farmácia \\
\hline ESF 04 & Auxiliar de farmácia \\
\hline ESF 05 & Auxiliar de farmácia \\
\hline ESF 06 & Auxiliar de farmácia \\
\hline ESF 07 & Técnica em enfermagem \\
\hline
\end{tabular}


Realidade e desafios das ESFs para a execução da primeira dose imediata de antibiótico para crianças em situação de doença

Um dos objetivos da campanha é o preparo do antibiótico pelo profissional, bem como a administração da primeira dose, de modo a ensinar o responsável pela criança a administrar as doses subsequentes.

O processo de dispensação dos medicamentos nas ESF é parte integrante do processo de cura, reabilitação e prevenção de doenças. Os medicamentos distribuídos neste nível de atenção são os chamados medicamentos essenciais, que segundo a Organização Mundial da Saúde, são aqueles que satisfazem as necessidades de cuidados de saúde básica da maioria da população que necessita não apenas receber, mas ser acompanhado e informado de sua ação e processo de administração (OMS, 2011).

O quadro 06 traz relatos dos entrevistados, com suas opiniões sobre a campanha primeira dose imediata de antibióticos.

Quadro 06 - Opinião dos enfermeiros sobre a campanha primeira dose imediata de antibiótico.

\begin{tabular}{|l|l|}
\hline \multicolumn{1}{|c|}{ RESPONDENTES } & \multicolumn{1}{c|}{ RELATOS } \\
\hline Enfermeiro 01 & $\begin{array}{l}\text { "O importante é o tratamento completo". } \\
\text { "Acho que tem outros problemas para resolverem." }\end{array}$ \\
\hline Enfermeiro 02 & $\begin{array}{l}\text { "Na comunidade a distribuição esta sendo eficaz, mas há casos onde a mãe } \\
\text { ou responsável não administra corretamente até o fim do tratamento, seria } \\
\text { muito bom se isso acontecesse. A administração não acontece nessa } \\
\text { unidade porque não foi implantado, mas se fosse seria bom". }\end{array}$ \\
\hline Enfermeiro 03 & $\begin{array}{l}\text { "Acho que a campanha tem um bom propósito, mas as unidades não estão } \\
\text { preparadas, tanto por falta de medicamentos quanto de profissionais". }\end{array}$ \\
\hline Enfermeiro 04 & $\begin{array}{l}\text { "Uma campanha mal estruturada e nosso município não irá aderir, já que } \\
\text { está funcionando bem a distribuição." }\end{array}$ \\
\hline Enfermeiro 05 & $\begin{array}{l}\text { "Como está acontecendo a distribuição de medicamentos está ótimo. Não } \\
\text { há necessidade de ser no posto de saúde". }\end{array}$ \\
\hline Enfermeiro 06 & $\begin{array}{l}\text { "A idéia é boa, já que há muitas pessoas desinformadas, que tomam e } \\
\text { administram o medicamento errado". }\end{array}$ \\
\hline Enfermeiro 07 & $\begin{array}{l}\text { "A distribuição do antibiótico é importante nas unidades de saúde. Porém a } \\
\text { administração da primeira dose, penso não ser necessário na unidade de } \\
\text { saúde, pois os pacientes moram perto da unidade e o cuidador é orientado a } \\
\text { iniciar o tratamento de imediato". }\end{array}$ \\
\hline
\end{tabular}

Avaliando as opiniões do pesquisados, percebe-se que os mesmo ainda não tem opinião positiva em relação à campanha. Na ESF 01 observa-se o desconhecimento sobre a importância da campanha e falta de iniciativa, também há certo comodismo da liderança, a qual acha esse novo desafio desnecessário. $\mathrm{Na}$ ESF 02 a enfermeira entrevistada relata a importância da realização da campanha já que é um problema vivenciado em sua unidade, mas que falta fortalecimento vindo da secretaria municipal de saúde, que ainda não implantou a campanha na cidade. $\mathrm{Na}$ ESF 03 a enfermeira relata as dificuldades na realização dessa campanha. $\mathrm{Na}$ ESF 04 a respondente demonstra total desconhecimento sobre a campanha e 
comodismo em relação ao funcionamento do sistema. Na ESF 05 também o responsável pela unidade não quer assumir novas responsabilidades em relação à saúde da criança, mesmo tendo recursos necessários. Na ESF 06 a respondente mostra interesse na campanha, já que a mesma trata de um problema de saúde pública que atinge toda comunidade. A respondente da ESF 07 demonstra desinteresse e falta de conhecimento sobre a real importância da realização da campanha, achando que essa responsabilidade é totalmente do cuidador parental.

\section{CONSIDERAÇÕES FINAIS}

A atenção à saúde da criança requer uma assistência adequada, pois é grande o índice de mortalidade infantil. Considerando que as doenças bacterianas são a segunda causa principal de óbito infantil, o ministério da saúde apoia a iniciativa da pastoral da criança na campanha primeira dose imediata de antibiótico e, divulga sua importância pela mídia. Mas além da divulgação a campanha requer materiais, estrutura e apoio dos profissionais para a implantação e realização desse projeto.

Quanto à realidade do município estudado observa-se que não é realizada a primeira dose supervisionada na unidade em que o antibiótico foi prescrito, evidencia-se também que a campanha não foi bem aceita pela maioria dos profissionais de saúde responsáveis pelas ESF. Segundo seus relatos uma pequena parcela é a favor da campanha e acredita que é um fator de fortalecimento da saúde das crianças, muitos dos profissionais entrevistados desconhecem a campanha e/ou referem como dificuldade o não apoio da secretaria do município.

Os desafios encontrados para realização são vários, onde a falta de conhecimento sobre a importância dessa campanha é o principal, pois para ser realizada a secretaria de saúde da cidade deve conhecer implantar e apoiar sua realização. Os dados apontam que as principais dificuldades relatadas pelos enfermeiros para a não realização dessa campanha são a falta de funcionários, adaptação da equipe para realização de nova tarefa, falta de medicamentos, estrutura física e falta de tempo. Todavia, quando na observação das unidades com o check-list, percebeu-se que alguns desses motivos poderiam ser excluídos, pois uma das dificuldades citadas é a falta de medicamentos, a qual foi avaliada e não é um problema real, pois a distribuição de medicamentos pelo almoxarifado central é semanal e acontece de acordo com a quantidade solicitada pela unidade, com base na média de consumo semanal. Outra dificuldade é a falta de estrutura física, a qual foi verificada in loco e percebeu-se que a maioria das unidades dispõe de espaço físico e materiais necessários.

Os outros motivos citados são adaptações da equipe, falta de funcionários e falta de tempo que são fatores que poderiam ser testados e tidos como desafios apenas se a campanha fosse realizada. 
Uma preocupação vista pela campanha é a administração da dose de antibiótico de forma incorreta tanto pelos "responsáveis" pela criança, quanto pelos funcionários que distribuem a medicação. Em relação a este fato, os dados coletados mostram que o medicamento é distribuído na maioria das unidades por um profissional com pouco conhecimento em medicamentos, preparação e efeitos adversos, assim a orientação quanto ao uso e preparo pode não ser exato, podendo o cuidador apresentar riscos de errar e não obter o sucesso do tratamento.

Outra consideração importante avaliada é a disponibilidade de recursos humanos disponíveis nas unidades, sendo verificado que todas as unidades têm médico clínico geral à disposição diariamente, pediatra semanalmente e materiais para atendimentos de urgência e emergência, sendo fatores importantes para a melhoria de qualidade na assistência e para um atendimento rápido, assim avaliando e prevenindo casos de óbitos infantis por doenças bacterianas as quais são evitáveis com o tratamento correto e em tempo hábil.

Após a análise e discussão dos dados concluiu-se que a campanha apesar de ser de grande importância não é efetiva no município e são vários os desafios a serem enfrentados. O município dispõe dos principais meios necessários para realização dessa campanha, a maioria das unidades dispõe de espaço físico e medicamentos necessários. Assim, a campanha pode ser realizada se houver incentivo e treinamento, por parte dos enfermeiros e dos gestores de saúde locais.

A realização dessa pesquisa deixa clara a importância de uma enfermagem ativa que busca novos desafios para qualidade da assistência e a evolução do processo de cuidado. O trabalho mostra que a informação é uma fonte de conhecimento e de apoio aos profissionais de saúde.

A campanha encabeçada pela pastoral da criança e também pesquisas semelhantes a esta, que foi realizada com uma pequena amostra de enfermeiros de um só município, pode ser a garantia de estímulo a mudanças necessárias e de simples execução, trazendo um atendimento de qualidade à criança e reduzindo assim os casos de mortes por falta de informações e oportunidades, e/ou falhas na rede de atenção.

\section{REFERÊNCIAS}

AGUIAR, Alvaro; MARTINS, Reinaldo Menezes, História da pediatria brasileira: coletânea de textos e depoimentos. Rio de Janeiro: Sociedade Brasileira de Pediatria, 1996.

ALCANTARA, Pedro; MARCONDES, Eduardo. Pediatria básica. São Paulo: Procienx, 1983. 
BOUFLEUR, Clovis, Rebidia: campanha primeira dose imediata; Curitiba, 2011. Disponível: <http://www.rebidia.org.br/index.php?option=com_content\& view=article\&id=440>. Acesso em: 10 mar. 2011.

BRASIL. Estatuto da Criança e do Adolescente: Lei nº 8.069 de 13 de junho de 1990. Florianópolis: Poder Judiciário, 2006. 2007. Ministério da Saúde. Revista de atenção farmacêutica. Rio de Janeiro,

COSTA, Manoel Otavio et al. Terapêutica clinica. Rio de Janeiro: Guanabara, 1998.

FERREIRA, José Paulo et al. Pediatria: diagnóstico e tratamento. Porto Alegre: Artmed, 2005.

NEUMANN, Zilda Arns. Campanha primeira dose imediata. Revista Informativa, Brasília, n. 67, 2011.

NÓRCIO, Lucia. Campanha recomenda antibiótico para criança. In: BRASIL. Ministério da Saúde. Saúde na mídia. Brasilia, 05 jul. 2011. Disponível em: <http://portal.saude.gov.br/portal/arquivos/pdf/clipping_05072011.pdf>. Acesso em: 10 mar. 2011

ORGANIZAÇÃO MUNDIAL DE SAÚDE (OMS). Dados Estatísticos Brasil, 2011. Disponível em: <http://www.who.int/countries/bra/es>. Acesso em: 12 set. 2011.

VERISSIMO, Maria De La Ó Ramallo et al . A formação do enfermeiro e a estratégia atenção integrada às doenças prevalentes na infância. Revista brasileira de enfermagem, Brasília, v. 56, n. 4, ago. 2003. Disponível em: <http://www.scielo.br/scielo.php?script= sci_arttext\&pid=S003471672003000400018\&lng=en\&nrm=iso>. Acesso em: 22 set. 2012.

Artigo recebido em: 02/03/2015

Artigo aprovado em: 26/01/2016 